\title{
Cushing syndrome in a child due to pro-opiomelanocortin (POMC) secretion from a yolk sac tumor
}

\author{
Evelien F Gevers ${ }^{1,+}$, Suzanne Meredith², Pratik Shah ${ }^{1,6}$, John Torpiano ${ }^{3}$, \\ Catherine Peters' ${ }^{1}$, Neil J Sebire ${ }^{4}$, Olga Slater ${ }^{5}$, Anne White ${ }^{2, *}$ and Mehul T Dattani ${ }^{1,6, *}$ \\ 1Department of Endocrinology, Great Ormond Street Hospital for Children, London, UK, ${ }^{2}$ Division of Diabetes, \\ Endocrinology and Gastroenterology, Faculty of Biology, Medicine and Health, University of Manchester, \\ Manchester Academic Health Sciences Centre, Manchester, UK, ${ }^{3}$ Department of Paediatrics, Paediatric Endocrine \\ Service, Mater Dei Hospital, Msida, Malta, ${ }^{4}$ Department of Histopathology, Great Ormond Street Hospital and \\ Institute for Child Health (UCL), London, UK, ${ }^{5}$ Department of Oncology, Great Ormond Street Hospital for \\ Children, London, UK, and ${ }^{6}$ Section of Genetics and Epigenetics in Health and Disease, Genetics and Genomic \\ Medicine Programme, UCL Institute of Child Health, London, UK \\ *(A White and M T Dattani contributed equally to this work) \\ ${ }^{\dagger}$ (EF Gevers is now at Department of Paediatric Endocrinology, Barts Health NHS Trust - Royal London Children's \\ Hospital, London, UK)
}

Correspondence should be addressed to A White or M T Dattani Email Anne.white@manchester.ac. uk or m.dattani@ucl.ac.uk

\begin{abstract}
Context: Pituitary microadenomas and adrenal tumours are the most common causes for endogenous Cushing syndrome (CS) in children.

Case description: We describe a two-year old girl with Cushing syndrome due to ectopic pro-opiomelanocortin (POMC) production from an abdominal yolk sac tumor. Cortisol concentrations were elevated but adrenocorticotropic hormone (ACTH) concentrations were equivocal. The use of antibodies specifically detecting ACTH precursors revealed that plasma ACTH precursors were elevated. Additionally, an ACTH assay with a low cross-reactivity for precursors showed low concentrations of ACTH. Immunohistochemistry suggested POMC but not ACTH production by the tumour.
\end{abstract}

Conclusion: We describe a yolk sac tumour as a novel source of ectopic POMC production leading to CS in a young girl.

\section{What's known on this subject}

In adults, ectopic ACTH syndrome is most often due to intrathoracic tumours, but cases of carcinoid tumours, neuroblastoma, phaeochromocytoma and carcinoma of the pancreas, thymus, thyroid and ovaries have been described.

\section{What this study adds}

To our knowledge, this is the first report of Cushing syndrome in a child due to POMC secretion from a yolk sac tumour.
() 2017 European Society of Endocrinology Printed in Great Britain

\section{Introduction}

Cushing syndrome (CS) is due to exposure to excess glucocorticoids. Clinical features include obesity, impaired growth, behavioural changes, facial plethora, hirsutism, muscle weakness and hypertension. Non-iatrogenic CS is rare (two to five per 1000000 per year) (1), and paediatric CS is even less common.

Pituitary microadenomas producing adrenocorticotropic hormone (ACTH) and adrenal tumours are the most common cause of endogenous paediatric CS. Ectopic ACTH syndrome (EAS) is extremely rare and accounts for less than one percent of the cases

Published by Bioscientifica Ltd. 
$(2,3)$. In adults, EAS is most often due to intrathoracic tumors, but cases of carcinoid tumours, neuroblastoma, pheochromocytoma and carcinoma of the pancreas, thymus, thyroid and ovaries have been described (4). We describe here, for the first time to our knowledge, a child with CS due to ectopic ACTH precursors from an abdominal yolk sac tumour.

In the human pituitary, POMC undergoes posttranslational processing, resulting in the production of pro-ACTH (further cleaved to ACTH, the N-terminal POMC fragment (N-POC) and a small joining peptide) and B-lipotrophin (B-LPH) (which is cleaved to produce G-lipotrophin (G-LPH) and B-endorphin (B-EP)) (Fig. 1A). All peptides, including POMC, are released into the circulation (5). Historically, ACTH precursors were identified as high-molecular-weight forms of ACTH in EAS tumors (6). More recently, the use of a specific twosite enzyme-linked immunosorbent assay (ELISA) using a pair of monoclonal antibodies, each recognizing a specific epitope in POMC, has enabled the measurement and identification of POMC $(5,7)$. We used this assay to gain insight into the aetiology of CS in this patient.

\section{Consent}

Informed and written consent were obtained from parents.

\section{Case presentation}

A 2.75-year-old girl presented with weight gain (five kilograms in 12 months), increased appetite, body odour, facial acne, pubic hair, lethargy and moodiness. She was the first child of Bulgarian and Maltese parents. There was no relevant medical history or family history.

Her weight and height were $18.75 \mathrm{~kg}(+2.69$ SDS) and $87.3 \mathrm{~cm}\left(-1.38\right.$ SDS) (BMI $\left.25 \mathrm{~kg} / \mathrm{m}^{2}\right)$. Weight gain in the last 2 months was $2.0 \mathrm{~kg}$, whereas height velocity was $0.7 \mathrm{~cm} /$ year. Blood pressure was $176 / 131 \mathrm{mmHg}$ $(>>+2$ SD). She had a Cushingoid appearance with round facies, facial acne, truncal obesity, mid-scapula fat pad and hypertrichosis. The abdomen was distended without hepatosplenomegaly or palpable masses. She also demonstrated proximal muscle weakness. Tanner stage was B1 P2 A1 M0 (Fig. 2).

Initial investigations showed an elevated midnight serum cortisol concentration $(1258 \mathrm{nmol} / \mathrm{L})$ with loss of circadian variation, increased cortisol excretion in four separate 24 -h urinary samples $(>1380 \mathrm{nmol} / 24 \mathrm{~h})$, incomplete suppression (22\%) of cortisol production on a low-dose dexamethasone suppression test (cortisol $1363 \mathrm{nmol} / \mathrm{L}$ at $0 \mathrm{~min}$ and 1468 and $1054 \mathrm{nmol} / \mathrm{L}$ at 24 and $48 \mathrm{~h}$ (normal $<1.8 \mu \mathrm{g} / \mathrm{dL},<50 \mathrm{nmol} / \mathrm{L}$ at $48 \mathrm{~h}$ )) and $43 \%$ suppression on a high-dose dexamethasone suppression test (Table 1). An ultrasound of the abdomen was normal.
A

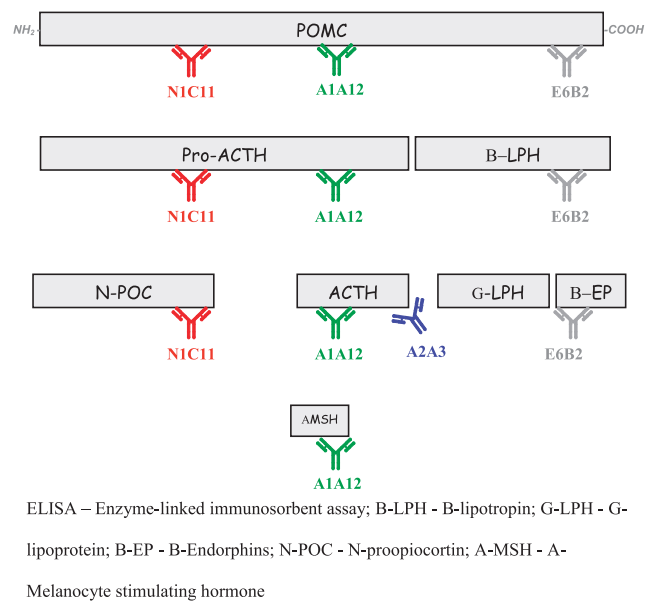

B

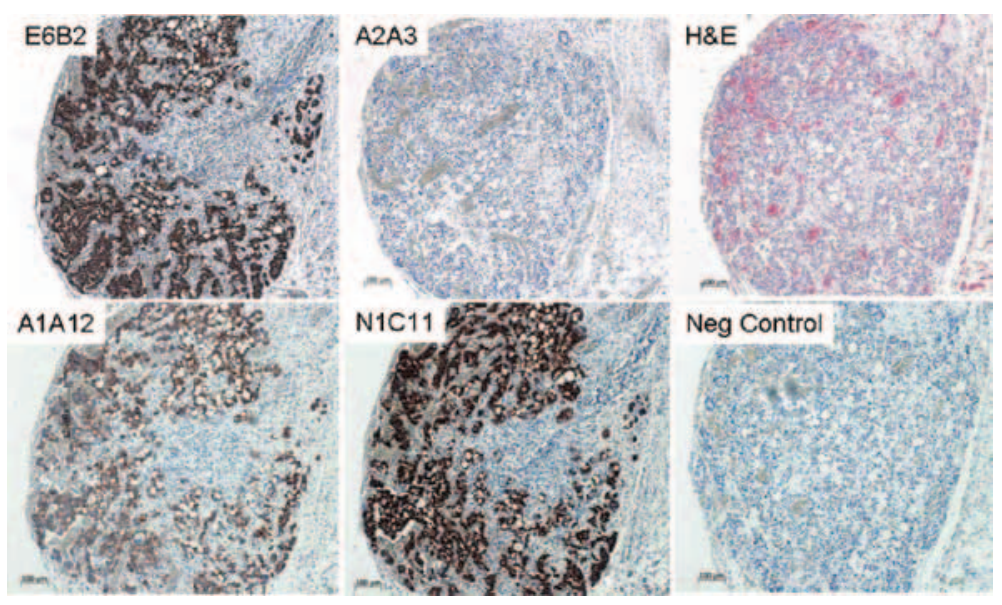

Figure 1

POMC but not ACTH is produced by the tumour. (A) Antibodies against epitopes in ACTH and ACTH precursors used in ELISAs and immunohistochemistry. (B) Immunohistochemistry of tumour sections using mouse antibodies to ACTH-related peptides and horseradish peroxidase-conjugated anti-mouse IgG. Staining with A1A12, N1C11 and E6B2 recognizing epitopes on ACTH precursors is positive (brown stain) but staining with $\mathrm{A} 2 \mathrm{~A} 3$, specific for $\mathrm{ACTH}$, is negative. Primary antibody is omitted in the negative control. A full colour version of this figure is available at http://dx.doi.org/10.1530/EJE-16-0776. 
A brain MRI showed a possible microadenoma in the left side of the pituitary.

The child was referred to Great Ormond Street Hospital for Children in London for further investigations. A 24-h serum cortisol profile showed no circadian rhythm with increased cortisol $(35.5 \mu \mathrm{g} / \mathrm{dL}, 985 \mathrm{nmol} / \mathrm{L})$ and ACTH concentration $(51.8 \mathrm{ng} / \mathrm{L}, 11.5 \mathrm{pmol} / \mathrm{L}$ (normal $<5 \mathrm{ng} / \mathrm{L})$ ) at midnight, and a morning ACTH of $39.9 \mathrm{ng} / \mathrm{L}$ (8.8 pmol/L, normal $10-50 \mathrm{ng} / \mathrm{L}$ ) (data not shown). A corticotropin-releasing hormone test (CRH test) (100 $\mathrm{\mu g}$ $\mathrm{CRH}$ ) showed a $12 \%$ increase in ACTH concentration and no clear increase in cortisol concentration from baseline (Table 2). The baseline production of other pituitary hormones was normal. Dihydroepiandrosterone-sulphate (DHEAS) and androstenedione were elevated. Potassium was low normal $(3.5 \mathrm{mmol} / \mathrm{L})$. The child had an episode of back pain and refused to walk. Orthopaedic investigations including spinal radiographs were normal, and she improved spontaneously.

The CRH test was inconsistent with pituitarydependent Cushing disease and EAS was considered. A thoracic CT-scan of the chest revealed marked nodular infiltration of the peritoneal surface of the diaphragm. A repeat abdominal ultrasound examination showed a solid pelvic mass $(3.5 \times 4.3 \times 3 \mathrm{~cm})$ and a solid heterogeneous infiltrating mass diffusely surrounding the liver and
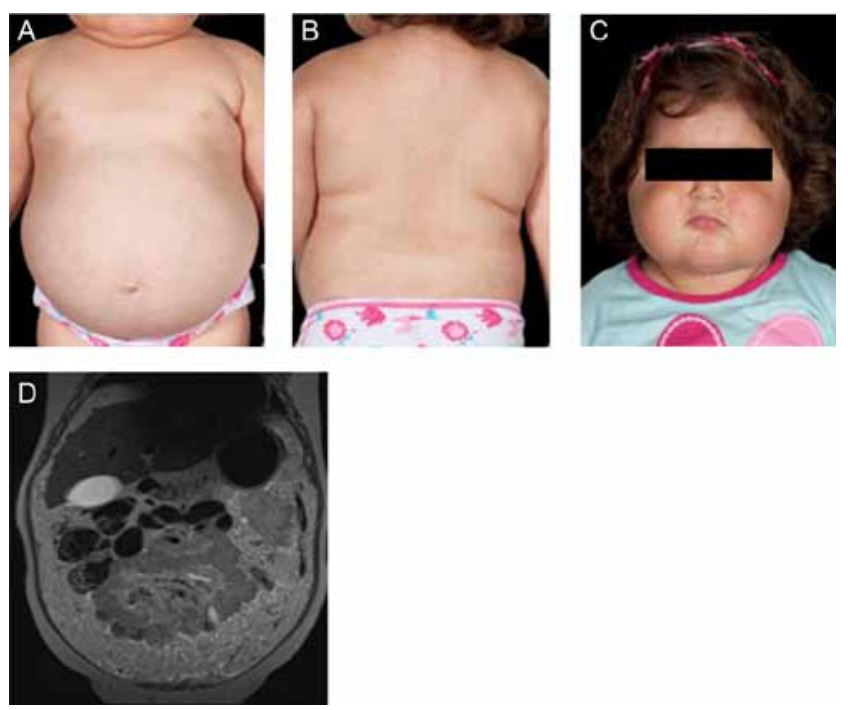

Figure 2

Clinical features of the patient described. (A, B and C) Clinical photographs showing Cushingoid features at the time of diagnosis. (D) MRI of the abdomen showing tumor and tumor invasion in peritoneum. A full colour version of this figure is available at http://dx.doi.org/10.1530/EJE-16-0776.
Table 1 Low-dose dexamethasone and high-dose dexamethasone suppression tests showed incomplete suppression ( $22 \%$ ) on low dose, and $43 \%$ suppression on a high dose dexamethasone suppression.

\begin{tabular}{|c|c|c|c|}
\hline Time & $\begin{array}{l}\text { Dexamethasone } \\
\text { dose }\end{array}$ & $\begin{array}{l}\text { Cortisol, } \boldsymbol{\mu g} / \mathbf{d L} \\
(\mathrm{nmol} / \mathrm{L})\end{array}$ & $\begin{array}{c}\text { ACTH, standard assay; } \\
\text { ng/L (pmol/L) (normal } \\
\text { range } 10-48 \text { ) }\end{array}$ \\
\hline 0 & Baseline & 76 (1363) & $18(4.0)$ \\
\hline$+24 h$ & $\begin{array}{l}\text { Low dose } \\
(10 \mu \mathrm{g} / \mathrm{kg} \text { four } \\
\text { times a day })\end{array}$ & 83 (1468) & - \\
\hline$+48 h$ & Low dose & 59 (1054) & $16(3.5)$ \\
\hline$+72 \mathrm{~h}$ & $\begin{array}{l}\text { High dose } \\
(40 \mu \mathrm{g} / \mathrm{kg} \text { four } \\
\text { times a day) }\end{array}$ & 55 (996) & - \\
\hline$+96 h$ & High dose & $43(770)$ & $15(3.3)$ \\
\hline
\end{tabular}

spleen (mimicking prominent adipose tissue) suggesting peritoneal infiltration by the tumour. Lymphadenopathy was present at the level of the porta hepatis. Abdominal MRI (Fig. 2) confirmed findings in keeping with malignant infiltrating peritoneal disease. Both adrenals appeared bulky without focal lesions. Alpha-feto protein (AFP) concentration was grossly elevated $(>300000 \mathrm{kU} / \mathrm{L})$, whereas B-HCG (human chorionic gonadotropin) was undetectable. A ${ }^{99}$ Technetium scan showed increased uptake in multiple ribs and vertebral bodies, femur and humerus compatible with metastatic bone disease. Bone marrow aspiration was normal.

Tumour needle biopsy demonstrated a primitive malignant epithelial tumour with no specific morphological features, expressing AE1/3 (cytokeratin), but CD117, Oct3/4, CD56, desmin, AFP, WT1 and S100 staining were negative. The child received Metyrapone and Ketoconazole, which successfully suppressed cortisol production. Further treatment consisted of five courses of Cisplatin, Doxorubicin and Etoposide, which led to reduction of AFP concentrations to $1264 \mathrm{kU} / \mathrm{L}$ and of cortisol production, so that Metyrapone and Ketoconazole could be stopped. The patient had multiple episodes of sepsis and neutropenia and was given PCP prophylaxis, and on one occasion had signs of possible thrombosis, but this improved spontaneously. Adrenal function was suppressed, and she required hydrocortisone replacement therapy. However, AFP concentrations increased again. Surgical resection was attempted, but multiple tumour plaques over the peritoneum and intra-abdominal organs prevented complete resection. AFP concentration fell from $17654 \mathrm{kU} / \mathrm{L}$ prior to surgery to $6590 \mathrm{kU} / \mathrm{L}$ after surgery. Histological examination of resected tissue 
Table 2 CRH test $(100 \mu \mathrm{g}$ CRH) showed a $12 \%$ increase in ACTH concentration measured by standard ACTH assay (see text for details) and no significant increase in cortisol concentration from baseline.

\begin{tabular}{|c|c|c|c|c|c|c|c|c|}
\hline & \multicolumn{8}{|c|}{ Time } \\
\hline & $-0 \mathrm{~h} 15 \mathrm{~min}$ & $0 \mathrm{~h} 00 \mathrm{~min}$ & Oh $15 \mathrm{~min}$ & $0 \mathrm{~h} 30 \mathrm{~min}$ & $0 \mathrm{~h} 45 \mathrm{~min}$ & $1 \mathrm{~h} 00 \mathrm{~min}$ & $1 \mathrm{~h} 30 \mathrm{~min}$ & $2 \mathrm{~h} 00 \mathrm{~min}$ \\
\hline Cortisol, $\mu \mathrm{g} / \mathrm{dL}$ (nmol/L) & $44.2(1228)$ & $47.4(1316)$ & $43(1195)$ & 46.7 (1297) & $49.5(1374)$ & $45.8(1272)$ & $46.4(1288)$ & $42.5(1181)$ \\
\hline ACTH, ng/L (pmol/L) & $27(5.9)$ & $39(8.6)$ & $43(9.5)$ & $34(7.5)$ & $38(8.4)$ & $40(8.8)$ & $40(8.8)$ & $32(7.0)$ \\
\hline
\end{tabular}

demonstrated sheets of malignant epithelial tumour expressing MNF116, CEA and AFP but not other markers such as desmin, vimentin, inhibin, WT1, calretinin, CD56, Oct3/4 and CD17; the overall features were strongly suggestive of a malignant yolk sac tumour. The tumour was graded as Grade IV (distant metastases).

\section{Methods}

\section{Identification of ectopic ACTH precursor production}

Plasma ACTH and ACTH precursors

Plasma ACTH was measured initially with a solidphase two-site chemiluminescent immunometric assay (Immulite 2000, Siemens) during diagnostic investigations. This assay has a sensitivity of $5 \mathrm{ng} / \mathrm{L}$ ( 1 pmol/L) and an inter-assay variability of $6-10 \%$. Cross-reactivity with ACTH precursors in this assay has recently been assessed to be $2.2 \%$ (8). After the first and second cycle of chemotherapy, ACTH and ACTH precursors (POMC and pro-ACTH) were measured by ELISA (in house) using the monoclonal antibodies N1C11 and A1A12. Binding of both antibodies to the ACTH precursors is required to generate a signal in the assay; therefore, ACTH or any of the other peptides derived from POMC and proACTH are not detected (9). The sensitivity of the precursor ELISA is $8 \mathrm{pmol} / \mathrm{L}$ and normal adult range of precursors is $7-32 \mathrm{pmol} / \mathrm{L}$ (10). Circulating concentrations of ACTH precursors above $100 \mathrm{pmol} / \mathrm{L}$ are indicative of an ectopic tumour $(5,11,12)$. Measurement of ACTH utilises MAb A1A12, which binds to ACTH $(10,11,12,13,14,15,16,17$, 18) and MAb A2A3 which binds the cleavage site of ACTH and therefore reduces the cross-reactivity with ACTH-precursors (Fig. 1A) (7). This ACTH ELISA has a sensitivity of $1 \mathrm{pmol} / \mathrm{L}$, variability $<10 \%$ and POMC cross-reacts $<3 \%$ (unpublished data).

\section{Immunohistochemistry for ACTH and precursors}

Paraffin sections of tumour biopsy were evaluated after antigen retrieval with mouse monoclonal antibodies A1A12, N1C11, E6B2 and A2A3, which recognise various epitopes of POMC and ACTH as described previously (11) (Fig. 1A). Staining was visualized using a Mouse Dako Envision+ System-HRP (DAB) and Gill's haematoxylin counterstain. Controls were rat pituitary sections (ACTH and POMC positive) and a DMS79 small-cell-lung cancer xenograft tumour (11), known to be POMC positive and ACTH negative.

\section{Results}

\section{Plasma ACTH and ACTH precursors}

In the first blood sample, taken before the second course of chemotherapy, ACTH precursors were detected at a concentration exceeding the normal adult range (7-32 pmol/L) (10), whereas ACTH concentrations (measured with the matching ACTH ELISA) were within the adult normal range. In the second sample, taken just before the 3rd cycle of chemotherapy, the ACTH precursor concentration had decreased considerably (Table 3). A small amount of 'ACTH' was detectable in both samples. It is very likely that this is due to the low cross-reactivity of ACTH precursors in the ACTH assay or endogenous ACTH secreted from the pituitary.

\section{Immunohistochemistry for ACTH and ACTH precursors in tumour sections}

The tumour showed strong cytoplasmic staining with antibodies A1A12 (recognizes ACTH and ACTH precursors), N1C11 (recognizes N-POC and ACTH precursors) and E6B2 (recognizes beta-endorphin and POMC) but not with the more specific ACTH antibody (A2A3) (Fig. 1B). This suggests the presence of POMC, but not mature ACTH, in tumour cells. Immunohistochemistry using A2A3 in a control POMC-producing xenograft tumour did not show any staining (data not shown), confirming the specificity of A2A3 for mature ACTH.

\section{Further treatment}

After establishment of the diagnosis of yolk sac tumour, treatment was changed to Paclitaxel, Ifosfamide and 
Table 3 Plasma concentration of ACTH precursors and ACTH after the first and second cycle of chemotherapy, measured by ELISA in duplicate (see text for details).

\begin{tabular}{|c|c|c|c|}
\hline Sample taken & Aliquot & $\begin{array}{c}\text { ACTH precursors } \\
(\mathrm{pmol} / \mathrm{L})\end{array}$ & $\begin{array}{c}\text { ACTH (ng/L) } \\
(\mathrm{pmol} / \mathrm{L})\end{array}$ \\
\hline \multirow[t]{2}{*}{ After 1st CT cycle } & $\bar{A}$ & 122 & $10.8(2.4)$ \\
\hline & B & 360 & $19.8(4.4)$ \\
\hline \multirow[t]{2}{*}{ After 2nd CT cycle } & $A$ & 79 & $10.8(2.4)$ \\
\hline & B & 70 & $14.0(3.1)$ \\
\hline
\end{tabular}

$\mathrm{CT}$, chemotherapy.

Cisplatin (TIP, 3 courses), after which AFP concentration fell to $2340 \mathrm{kU} / \mathrm{L}$ and tumour size decreased to $2.7 \times 3.2 \mathrm{~cm}$ with only discrete areas of disease intraperitoneally. A further TIP course and high-dose chemotherapy (Paclitaxel, Carboplatin, Etoposide and Cyclophosphamide) with autologous peripheral blood stem cell rescue was given. Despite this, AFP increased again (26444 kU/L; Fig. 3). Hyperthermic intraperitoneal

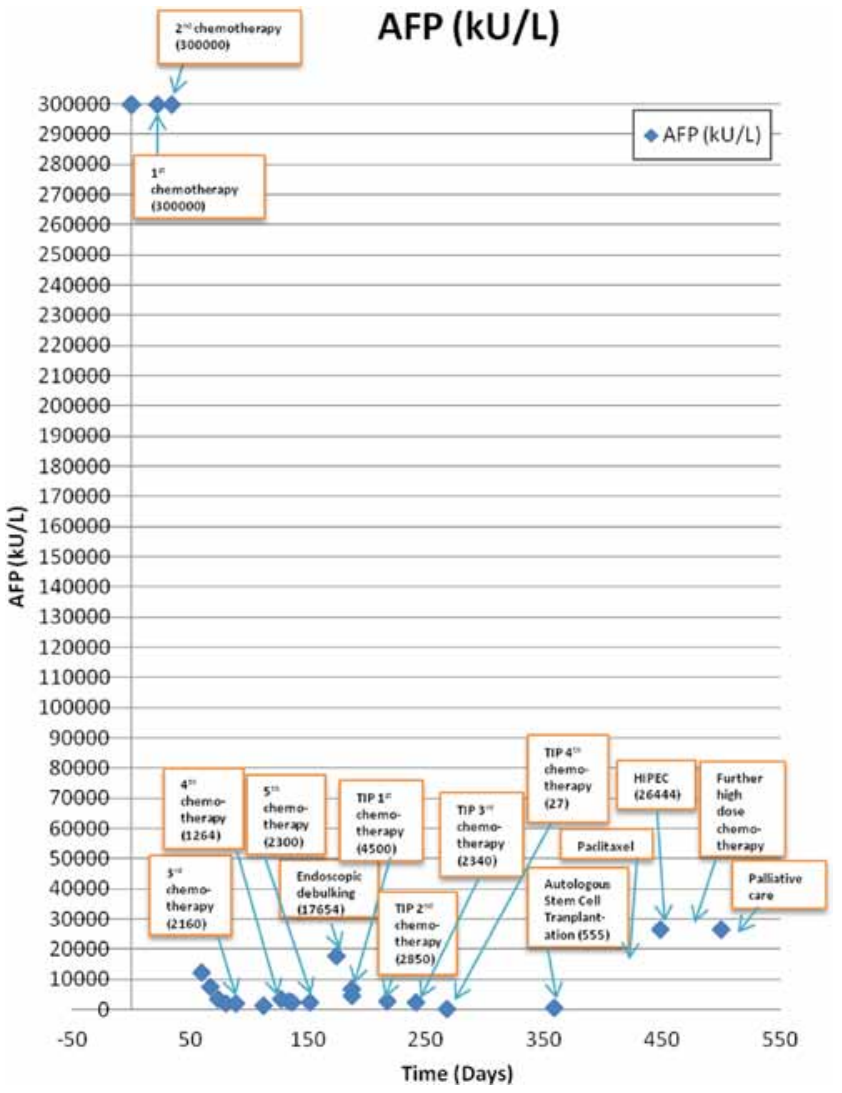

\section{Figure 3}

Chronology of AFP concentration and interventions.

Concentration of AFP was severely raised at diagnosis and responded to interventions but never normalized, in line with the tumour relapses and metastases. chemotherapy (HIPEC) was administered without longterm success. She further received Gemcitabine, Docetaxel and Metronomic chemotherapy with Cyclophosphamide and Etoposide (13). Whole abdominal radiotherapy in a dose effective for treatment of germ cell tumours (54Gy) was not possible to deliver. She then continued to receive palliative chemotherapy and unfortunately passed away 1.5 years later.

\section{Discussion}

We describe, for the first time to our knowledge, POMC production from a malignant yolk sac tumour as the cause of CS due to 'ectopic ACTH precursor production' in a child. Yolk sac tumours (endodermal sinus tumours) are a malignant subtype of germ cell tumour $(14,15)$, characterized typically by AFP and Gli-3 immunoreactivity and may occur in both gonadal and extra-gonadal tissues. Reports of EAS in adults due to ACTH production in teratoma $(16,17)$, ovarian epithelial $(18,19)$ and ovarian endometrial carcinoma (20) exist but EAS has not previously been described in a yolk sac tumour. Two large case series of 90 adults at NIH and 40 adults in London with EAS have recently been published, but yolk sac tumour was not identified as a cause for EAS $(21,22)$.

Another recent case series described ten children with EAS identified during the last 20 years in France (23). Seven patients had thoracic neuro-endocrine tumors; one had a liver nested stromal epithelial tumor, one a carcinoma of the thymus and one Ewing's sarcoma. Of note, positive ACTH staining of the tumour was one of the inclusion criteria. Therefore, POMC/pro-ACTH-producing tumours may not have been included, depending on the antibodies used for ACTH detection.

To identify the aetiology of the CS in our patient, four different antibodies were used in plasma ELISAs and tumour immunohistochemistry. The ACTH precursor ELISA, which measures both POMC and pro-ACTH, gave the first indication that plasma ACTH precursor concentrations were increased. IHC staining of the tumour with A1A12, N1C11 and, also, E6B2, which binds to POMC but not pro-ACTH, showed positive staining. This is strong evidence that the tumour produced POMC but did not cleave it to mature ACTH. Additionally, the tumour did not stain with A2A3, which is specific for mature ACTH. In addition, the POMC concentration decreased after chemotherapy, in line with reduction in tumour size and improvement of features of CS. 
These data suggest that either POMC is binding to the ACTH receptor (melanocortin-2 receptor, MC2-R), in the adrenal gland to stimulate cortisol secretion or that POMC is cleaved in the adrenal gland to allow ACTH to bind and stimulate cortisol secretion. Indeed, other patients with ectopic 'ACTH' syndrome due to ACTH precursor production have clinical symptoms $(24,25)$, also suggesting that ACTH pre2cursors bind to the adrenal MC2-R or are locally cleaved. Although it has not been possible to investigate the bioactivity of POMC because of the high concentrations of purified POMC that are required, we have shown that POMC can bind to the MC1-R (26).

Differentiation between an ACTH-producing pituitary adenoma (Cushing Disease, CD) and EAS can be difficult. No single biochemical test can differentiate between the two and responses to dynamic function tests overlap. Bilateral inferior petrosal sinus sampling (BIPSS) (23) remains the golden standard to differentiate pituitary Cushing and EAS (27), but it is difficult to perform, particularly in children. This case illustrates the potential usefulness of measurement of ACTH precursors to differentiate between CD and EAS. Peripheral concentrations of ACTH precursors are low in CD and high in EAS and a clear relation exists between BIPSS results and baseline ACTH precursor concentration (7). Stewart et al. (24) reported that ACTH precursor assessment (by immunoradiometric assay) showed a $100 \%$ sensitivity and specificity in a group of EAS patients and CD patients. Levels of ACTH precursors were between 139 and $18000 \mathrm{pmol} / \mathrm{L}$ in EAS patients, between 8 and $73 \mathrm{pmol} / \mathrm{L}$ in the CD patients and below $40 \mathrm{pmol} / \mathrm{L}$ in control subjects. Measuring ACTH precursors can also distinguish the majority of occult ectopic 'ACTH'producing tumours that are not detected by MRI. PageWilson et al. (10) showed that in their patient cohort, 7 of 11 such patients could be distinguished by ACTH precursor measurement alone. This gives a sensitivity of $64 \%$ and specificity of $100 \%$.

Yolk sac tumours are chemosensitive but when complete resection is not feasible, and there is cisplatin resistance, relapse is frequent and the outcome is poor, as seen in this case (28). Medical treatment of EAS with Metyrapone and Ketoconazole is effective in decreasing cortisol production, but is of limited use due to side effects.

Complications of EAS include increased susceptibility for infections and thrombosis. Therefore, if possible, chemotherapy is started only when cortisol production is controlled pharmacologically. Antibiotic prophylaxis, PCP prophylaxis and anti-coagulation could be considered, but currently no guidelines or evidence base exists to do this in paediatric EAS.

To conclude, we used antibodies to different epitopes on ACTH precursors in ELISAs and immunohistochemistry to demonstrate, for the first time, POMC production in a disseminated malignant yolk sac tumor as the underlying cause of CS in a two-year-old child. Hence, a diagnosis of aggressive Cushing syndrome in the face of normal ACTH concentrations should prompt a search for ACTH precursors in EAS.

Declaration of interest

The authors declare that there is no conflict of interest that could be perceived as prejudicing the impartiality of the research reported.

\section{Funding}

M T D is funded by Great Ormond Street Hospital Children's Charity. A W and S M were partly funded by the Manchester Academic Health Sciences Centre and the Manchester Biomedical Research Centre.

\section{Author contribution statement}

E G contributed to writing the manuscript, literature search, data collection and interpretation; S M contributed to writing the manuscript, figures and carrying out immunohistochemistry; P S contributed to writing the manuscript, data collection and interpretation; J T contributed to writing the manuscript; C P contributed to writing the manuscript; $\mathrm{N} S$ contributed to writing the manuscript and providing histopathology report; O S contributed to writing the manuscript and clinical management of the patient; A W contributed to writing the manuscript, data collection, figures and carrying out immunohistochemistry; M T D contributed to writing the manuscript, literature search, data collection and interpretation of figures.

\section{Acknowledgements}

The authors thank the patient's family for their permission and consent to report these findings and pictures.

\section{References}

1 Lindholm J, Juul S, Jorgensen JO, Astrup J, Bjerre P, Feldt-Rasmussen U, Hagen C, Jorgensen J, Kosteljanetz M, Kristensen $\mathrm{L}$ et al. Incidence and late prognosis of cushing's syndrome: a population-based study. Journal of Clinical Endocrinology and Metabolism 200186 117-123. (doi:10.1210/jc.86.1.117)

2 Batista DL, Riar J, Keil M \& Stratakis CA. Diagnostic tests for children who are referred for the investigation of Cushing syndrome. Pediatrics 2007120 e575-e586. (doi:10.1542/peds.2006-2402)

3 Storr HL, Chan LF, Grossman AB \& Savage MO. Paediatric Cushing's syndrome: epidemiology, investigation and therapeutic advances. Trends in Endocrinology and Metabolism 200718 167-174. (doi:10.1016/j.tem.2007.03.005)

4 Ejaz S, Vassilopoulou-Sellin R, Busaidy NL, Hu MI, Waguespack SG, Jimenez C, Ying AK, Cabanillas M, Abbara M \& Habra MA. Cushing syndrome secondary to ectopic adrenocorticotropic hormone secretion: the University of Texas MD Anderson Cancer Center Experience. Cancer 2011117 4381-4389. (doi:10.1002/cncr.26029) 
5 Gibson S, Crosby SR, Stewart MF, Jennings AM, McCall E \& White A. Differential release of proopiomelanocortin-derived peptides from the human pituitary: evidence from a panel of two-site immunoradiometric assays. Journal of Clinical Endocrinology and Metabolism 199478 835-841. (doi:10.1210/jc.78.4.835)

6 Yalow RS \& Berson SA. Size heterogeneity of immunoreactive human ACTH in plasma and in extracts of pituitary glands and ACTH-producing thymoma. Biochemical and Biophysical Research Communications 197144 439-445. (doi:10.1016/0006-291X(71)90620-6)

7 Oliver RL, Davis JR \& White A. Characterisation of ACTH related peptides in ectopic Cushing's syndrome. Pituitary 20036 119-126. (doi:10.1023/B:PITU.0000011172.26649.df)

8 Monaghan PJ, Kyriacou A, Sturgeon C, Davies A, Trainer PJ, White A $\&$ Higham CE. Proopiomelanocortin interference in the measurement of adrenocorticotrophic hormone: a United Kingdom National External Quality Assessment Service study. Clinical Endocrinology 2016 85 569-574. (doi:10.1111/cen.13118)

9 Crosby SR, Stewart MF, Ratcliffe JG \& White A. Direct measurement of the precursors of adrenocorticotropin in human plasma by two-site immunoradiometric assay. Journal of Clinical Endocrinology and Metabolism 198867 1272-1277. (doi:10.1210/jcem-67-6-1272)

10 Page-Wilson G, Freda PU, Jacobs TP, Khandji AG, Bruce JN, Foo ST, Meece K, White A \& Wardlaw SL. Clinical utility of plasma POMC and AgRP measurements in the differential diagnosis of ACTHdependent Cushing's syndrome. Journal of Clinical Endocrinology and Metabolism 201499 E1838-E1845. (doi:10.1210/jc.2014-1448)

11 Stovold R, Meredith SL, Bryant JL, Babur M, Williams KJ, Dean EJ, Dive C, Blackhall FH \& White A. Neuroendocrine and epithelial phenotypes in small-cell lung cancer: implications for metastasis and survival in patients. British Journal of Cancer $2013 \mathbf{1 0 8}$ 1704-1711. (doi:10.1038/bjc.2013.112)

12 Russell GM, Henley DE, Leendertz J, Douthwaite JA, Wood SA, Stevens A, Woltersdorf WW, Peeters BW, Ruigt GS, White A et al. Rapid glucocorticoid receptor-mediated inhibition of hypothalamic-pituitaryadrenal ultradian activity in healthy males. Journal of Neuroscience 2010 30 6106-6115. (doi:10.1523/JNEUROSCI.5332-09.2010)

13 Hayes-Jordan A, Green H, Ludwig J \& Anderson P. Toxicity of hyperthermic intraperitoneal chemotherapy (HIPEC) in pediatric patients with sarcomatosis/carcinomatosis: early experience and phase 1 results. Pediatric Blood and Cancer 201259 395-397. (doi:10.1002/pbc.24160)

14 Nogales FF, Preda O \& Nicolae A. Yolk sac tumours revisited. A review of their many faces and names. Histopathology 201260 1023-1033. (doi:10.1111/j.1365-2559.2011.03889.x)

15 Dallenbach P, Bonnefoi H, Pelte MF \& Vlastos G. Yolk sac tumours of the ovary: an update. European Journal of Surgical Oncology 200632 1063-1075. (doi:10.1016/j.ejso.2006.07.010)

16 Moreno-Fernández J, Gutiérrez-Alcántara C, Gálvez Moreno MA, Jiménez-Reina L, Castaño JP \& Benito-López P. Corticotrophindependent Cushing syndrome due to Sacrococcygeal Teratoma detected by [18F]fluorodeoxyglucose positron emission tomography. Journal of Clinical Endocrinology and Metabolism 200893 3282-3283. (doi:10.1210/jc.2008-0458)
17 Axiotis CA, Lippes HA, Merino MJ, deLanerolle NC, Stewart AF \& Kinder B. Corticotroph cell pituitary adenoma within an ovarian teratoma. A new cause of Cushing's syndrome. American Journal of Surgical Pathology 198711 218-224. (doi:10.1097/00000478198703000-00007)

18 Parsons V \& Rigby B. Cushing's syndrome associated with adenocarcinoma of the ovary. Lancet 19582 992-994. (doi:10.1016/ S0140-6736(58)90479-3)

19 Kasperlik-Zauska AA, Jeske W \& Migdalska B. Cushing's syndrome secondary to ectopic ACTH secretion from a primary ovarian carcinoma. Clinical Endocrinology 199747 501-502.

20 Khan MI, Waguespack SG, Habra MA, Broaddus R \& Jimenez C. Acute-onset ectopic adrenocorticotropic hormone syndrome secondary to metastatic endometrioid carcinoma of the ovaries as a fatal complication. Journal of Clinical Oncology 201129 e462-e464. (doi:10.1200/JCO.2010.34.3848)

21 Ilias I, Torpy DJ, Pacak K, Mullen N, Wesley RA \& Nieman LK. Cushing's syndrome due to ectopic corticotropin secretion: twenty years' experience at the national institutes of health. Journal of Clinical Endocrinology and Metabolism 200590 4955-4962. (doi:10.1210/jc.2004-2527)

22 Isidori AM, Kaltsas GA, Pozza C, Frajese V, Newell-Price J, Reznek RH, Jenkins PJ, Monson JP, Grossman AB \& Besser GM. The ectopic adrenocorticotropin syndrome: clinical features, diagnosis, management, and long-term follow-up. Journal of Clinical Endocrinology and Metabolism 200691 371-377. (doi:10.1210/jc.2005-1542)

23 More J, Young J, Reznik Y, Raverot G, Borson-Chazot F, Rohmer V, Baudin E, Coutant R \& Tabarin A. Ectopic ACTH syndrome in children and adolescents. Journal of Clinical Endocrinology and Metabolism 201196 1213-1222. (doi:10.1210/jc.2010-2276)

24 Stewart PM, Gibson S, Crosby SR, Penn R, Holder R, Ferry D, Thatcher N, Phillips P, London DR \& White A. ACTH precursors characterize the ectopic ACTH syndrome. Clinical Endocrinology 1994 40 199-204. (doi:10.1111/j.1365-2265.1994.tb02468.x)

25 White A, Ray DW, Talbot A, Abraham P, Thody AJ \& Bevan JS. Cushing's syndrome due to phaeochromocytoma secreting the precursors of adrenocorticotropin. Journal of Clinical Endocrinology and Metabolism 200085 4771-4775. (doi:10.1210/ jc.85.12.4771)

26 Rousseau K, Kauser S, Pritchard LE, Warhurst A, Oliver RL, Slominski A, Wei ET, Thody AJ, Tobin DJ \& White A. Proopiomelanocortin (POMC), the ACTH/melanocortin precursor, is secreted by human epidermal keratinocytes and melanocytes and stimulates melanogenesis. FASEB Journal 200721 1844-1856. (doi:10.1096/fj.06-7398com)

27 Lacroix A, Feelders RA, Stratakis CA \& Nieman LK. Cushing's syndrome. Lancet 2015386 913-927. (doi:10.1016/S01406736(14)61375-1)

28 Gobel U, Calaminus G, Schneider DT, Schmidt P, Haas RJ, the SIOP CNS GCT Study Group MAKEI \& MAHO Study Groups of the German Society of Pediatric Oncology and Hematology. Management of germ cell tumors in children: approaches to cure. Onkologie 200225 14-22. (doi:10.1159/000055197)

Received 11 September 2016

Revised version received 14 November 2016

Accepted 22 November 2016 